\title{
Economic Evaluation of an Eye Hospital in Terms of Net Present Value and Profitability Index
}

\author{
${ }^{1}$ Shibu John, ${ }^{2}$ Komal Dabas, ${ }^{3}$ Iffat Naseem
}

\begin{abstract}
Introduction: Hospital projects are highly cost intensive and therefore, it takes few years to become a profit oriented entity. The success of these hospital projects can be measured through various economic evaluation methods. Economic evaluation can also be called as an effort to analyze inputs and outputs together and logically help decision makers evaluate whether a certain level of output is worth the amount of resources expended to produce it.
\end{abstract}

Method of the study: The present study was planned to do the economic evaluation of an Eye hospital, in Haryana state. Two parameters were considered for evaluating the project, i.e. Net Present Value (NPV) and Profitability Index (PI). The data used in the study was from 2010-2011 to 2016-2017. This includes actual and projected data.

Result and conclusion: A positive NPV explain the project is worthwhile and making profits, with current cost and revenue projections. PI for this center is found out to be 3.47 which also emphasize that the project is a value for money proposition.

Keywords: Economic evaluation, Net present value, Profitability index.

How to cite this article: John S, Dabas K, Naseem I. Economic Evaluation of an Eye Hospital in Terms of Net Present Value and Profitability Index. Int J Res Foundation Hosp Healthc Adm 2014;2(1):36-40.

\section{Source of support: Nil \\ Conflict of interest: None}

\section{INTRODUCTION}

Economic evaluation is a 'comparative analysis of alternative courses of action in terms of both their costs and returns. ${ }^{1}$ It can also be called as an effort to analyze inputs and outputs together and logically help decision makers evaluate whether a certain level of output is worth the amount of resources expended to produce it. Two essential

\footnotetext{
${ }^{1}$ Associate Professor, ${ }^{2}$ Assistant Operations Manager ${ }^{3}$ Management Associate

${ }^{1,3}$ Department of Management, Jamia Hamdard University New Delhi, India

${ }^{2}$ Eye Q Super Speciality Eye Hospital, Gurgaon, Haryana, India
}

Corresponding Author: Shibu John, Associate Professor Department of Management, Jamia Hamdard University, New Delhi, India, Phone: 91-9873668705, e-mail:shibu.john14@ gmail.com features of this definition are worth noting. Firstly, economic evaluation involves a comparison between alternative courses of action. Secondly, the options are evaluated in terms of both their costs and their benefits. The oldest type of economic evaluation is cost benefit analysis through which questions primarily of allocative efficiency are addressed. Even if not everything can be valued in monetary terms, a cost-benefit framework is still useful as all impacts on costs and benefits can be laid out in a 'balance sheet' to highlight where trade-offs can be, or are being made between tangible items (usually costs) and some intangibles. ${ }^{2}$

With the rise in healthcare costs, it is very essential to economically evaluate the healthcare units so as to find the ways of increasing the profits and minimize costs and wastage. ${ }^{3}$ Health care economic analyses are becoming increasingly important in the evaluation of healthcare interventions, including many within ophthalmology. Encompassed with the realm of healthcare economic studies are cost-benefit analysis, cost-effectiveness analysis, costminimization analysis, and cost-utility analysis. ${ }^{5}$ These specific techniques of economic evaluation can be used to address whether a program, project or intervention offers good value of money. The techniques of economic evaluation offer a systematic framework for identifying, measuring and valuing the resource inputs (costs) to a healthcare project and associated benefits (health outcomes and revenue generated).

Apart from the patient care, budgeting and revenue generation are two important areas which are looked upon by the hospital managers. The main focus is to minimize the costs and maximize the earned revenue. To do so, the management must have thorough understanding of the costs involved in the system and the outcomes and benefits as to ensure that the hospital project is a valuable proposition or not. Resources are scarce, especially healthcare resources. Therefore all organization's involved in healthcare are concerned with the securing value for money from their investments. Organizations need to be able to calculate the return precisely, a project yields. When a cost-benefit analysis is performed, a comparative assessment of all the anticipated benefits from the project and all the costs to introduce the project, operationalize and support it, are identified. 
Cost-benefit analyses help to:

- Decide whether to undertake a project or decide which of several projects to undertake.

- Frame appropriate project objectives.

- Develop appropriate before and after measures of project success.

- Prepare estimates of the resources required to perform the project work.

Thus, a cost-benefit analysis is most helpful tool in management arsenal. The present study was planned to do the economic evaluation at an Eye hospital, in Haryana state. The main aim of the study is to analyse whether the center is viable or not.

The costs involves in the economic evaluation could be resource costs: capital costs (new and existing buildings or equipment); staffing costs (physicians, nurses, physiotherapists, etc.); consumable costs (drugs, dressings, etc.); nonpatient related costs (administration and overhead costs); costs incurred in nonhealth care sectors (social services, etc.); and costs incurred by patients and their families (transportation, parking, child care, etc.). ${ }^{9}$ These costs could be fixed or variable. The outcomes could be in terms of health utility, Quality Adjusted Life Years (QALY), revenue and time trade-offs. ${ }^{2}$ An economic evaluation study carried out by Goor et al (2010) compared the costs involved at the hospital's end in glaucoma follow-up group and glaucoma specialist group assuming that the health outcomes in both the groups are same. ${ }^{4}$ The results of the study showed that healthcare costs were significantly lower in glaucoma follow-up unit. Thus, this method of treatment could be adopted at other eye hospitals as well.

When considering the role of economic evaluation in health technology assessment, identify four stages at which economic evaluation can take place. ${ }^{6}$ These are early developmental (stage 1); maturing innovation (stage 2); close to widespread diffusion (stage 3); and moving into practice (stage 4). Stage 1 comprises the systematic review of evidence relating to the cost and effectiveness of existing experience and the use of informal clinical opinion to assess the potential value of the new technology. Stage 2 includes modeling studies using the data from existing clinical studies, and the pilot studies of economic data collection alongside controlled trials. Stage 3 involves economic data collection alongside RCTs and refined modeling studies using systematic overviews of clinical data. Finally, stage 4 involves economic data collection alongside pragmatic trails and modeling studies to generalize results to other settings or to extrapolate to the long-term.

Tallying up all the cost components may yield overlapping areas of similar resource use, such as two variously busy clinics (one a very busy clinic and the other a not so busy clinic). In this case it becomes difficult to disentangle the true proportion of overhead expenses (electricity, heat, rent of hospital space, etc.) which is being consumed separately. Under such circumstances, the aim is to make a reasonable estimate of the various amounts involved, including such matters as the number of employees, the size or area of clinic space used, the number and volume of patients seen, etc. ${ }^{8}$

As a general rule, if an investment has a positive $(+)$ profitability index $(>1)$, then the project should be undertaken. However, if an investment has a negative (-) profitability index $(<1)$, the project should be rejected.

- If PI $>1$, Good Investment

- If PI $<1$, Bad Investment

There exists a linear relationship between NPV and PI.

- If profitability index $>1, \mathrm{NPV}$ is positive $(+)$.

- If profitability index $<1, \mathrm{NPV}$ is negative $(-)$.

\section{OBJECTIVES}

Broad objective of the study is to do cost benefit analysis to understand the financial return of the eye center project. However, the specific objectives of the study are to:

1. Calculate the total year wise costs involved in the eye center.

2. Study the revenue pattern of the center through various procedures.

3. Calculate net present value and profitability index.

\section{RESEARCH METHODOLOGY}

The study is both descriptive and exploratory in nature. All the cost and revenue were taken from the audited finance records. A performa was made to identify different types of cost since hospital's inception. A separate sheet was prepared to calculate the year wise revenue from the patient and medical and consumable store.

\section{The Present Value Concept}

A project will be worth doing if the total of its benefits is at least as high as the sum of its costs, measured in monetary terms. Given that benefits and costs will continue over several years, and that the value of rupee today are worth more than the promise of rupees next year, both situation must be converted to a common time period, conventionally taken to be the present period. Accordingly, the net benefit of the project will be its net present value (NPV), defined as the present value of the benefits (PVB) less the present value of the costs (PVC). Net present value concept is a management tool to improve decision-making, taking. Discounting concept into account. The discounting part take cares the inflation while calculating present value for a project. 


\section{Profitability Index}

Profitability is an important parameter (ratio) that explains the relationship between the costs of a project and benefits in terms revenue. The value of 1 is taken as minimum acceptable measure on this index. ${ }^{7}$ Any value less than one, would indicate that the project's present value is lower than original investment. As the values of the profitability index (PI) increase, so does the financial return and worthiness of the proposed project. PI quantify the amount of value created per unit of investment. It is significantly different from return on investment which is used to evaluate the efficiency of an investment or to compare the efficiency of various investments options.

\section{Data Collection Plan}

The data used in the study was from 2010-2011 to 2016-2017. This includes actual and projected data. For the calculation purpose, year 2010 is considered as year zero. The data for the 0 to 3 years is the real time data. Remaining data is projected based on the trend seen from the actual data.

- 0 year initial investment

- 1 years: Oct 2010 to Mar 2011

- 2 years: Apr 2011 to Mar 2012

- 3 years: Apr 2012 to Mar 2013

- 4 years: Apr 2013 to Mar 2014

- 5 years: Apr 2014 to Mar 2015

- 6 years: Apr 2015 to Mar 2016

- 7 years: Mar 2016 to Apr 2017

The study is done based on the data collected or projected from 2010 to 2017. The main reason for taking these 7 years time frame is because of two facts, one that major equipments installed in the center were procured in the year 2013 and these equipments life is considered as 5 years. Secondly, the building is on lease agreement till 2017.

\section{Data Analysis}

Cost benefit analysis is done by calculating NPV and PI. Following formula is used to calculate both these indicators.

Net present value $(\mathrm{NPV})={ }_{0} \sum^{n} R t /(1+i)^{t}$

$R t=$ Net Gain or profit (total revenue-total cost)

$i=$ Discount rate. It is taken as $10 \%$ in this study $n=$ No. of years

Profitability index $=\frac{\mathrm{NPV}+\text { Initial capital investment }}{\text { Initial capital investment }}$

\section{STUDY FINDINGS}

Total expenditure year wise on the project, were divided into capital expenditure and running expenditure for different years. Capital expenditure includes cost of purchase of equipment, hospital information system (LEKHI), software licence, hardware costs and furnishing and other costs. Running expenditure includes the rent, cost of consumables, salary of the permanent employee and visiting consultants (Allocated Cost), petty cash for routine expenditure and yearly software licence renewal cost. Marketing expenses, staff and patient welfare expenses, travel expenses, phone bill, electricity bill, water bill and local vendor payment for supplies, repair and maintenance cost are included in petty cash. Total initial investment for the hospital in year zero is mentioned in Table 1 . These costs are only the initial capital investment for the project.

The project was launched in the year 2010. Table 2 shows the year wise total costs incurred by the center under various heads. In the Table 2, cost from 2010-2011 to 2012-2013 are real time data and from 2013-2014 to 2016-2017 are the projected costs based on the trend seen in past 2 to 3 years. While making the projections, opinion of the promoters were also taken to understand if they have any immediate future investment plan. For making the calculation few assumptions were made, e.g. cost projections were made for the period 2013-2014 to 2016-2017 for different cost heads, e.g., consumables @ 15\% increase annually, salary $15 \%$ increase annually and petty cash $25 \%$ annually. Rent and software renewal will remain same year as it is under long-term-agreement.

The revenue generating departments include OPD, cataract clinic, retina clinic, glaucoma clinic, Lasik clinic, occuloplasty services, squint clinic and pediatric eye services. The revenue is generated by performing diagnostic tests and carrying out surgeries in different clinics. Table 3 shows the year wise revenue generated by different specialties and the total revenue. It is observed from the Table 4 that from 2010 to 2013, revenue showed 20\% increase annually and this is used as basis of revenue projections.

Graph 1 shows the graphical representation of the revenue pattern from 2010-2011 to 2016-2017.

Table 1: Capital investment in year zero

\begin{tabular}{lllll}
\hline S. no. & $\begin{array}{l}\text { Capital } \\
\text { expenditure }\end{array}$ & Rate (in ₹) & Amount (in ₹) & $\begin{array}{l}\text { Share } \\
\text { (\%) }\end{array}$ \\
\hline 1 & $\begin{array}{l}\text { Equipment } \\
\text { (complete) }\end{array}$ & 21950701 & 95.4 \\
2 & $\begin{array}{l}\text { Lekhi Software } \\
\text { (11 centers) }\end{array}$ & & \\
& 2000000 & 181818 & 0.8 \\
3 & $\begin{array}{l}\text { Licence per } \\
\text { center }\end{array}$ & 200000 & 200000 & 0.9 \\
4 & Hardware cost 280000 & 280000 & 1.2 \\
5 & $\begin{array}{l}\text { Furnishing and } 400000 \\
\text { other cost }\end{array}$ & 400000 & 1.7 \\
\hline & Total & 23012519 & 100 \\
\hline
\end{tabular}


Economic Evaluation of an Eye Hospital in Terms of Net Present Value and Profitability Index

\begin{tabular}{lcccccccc}
\hline \multicolumn{7}{c}{ Table 2: Year-wise expenditure (actual and projected) } \\
\hline Year & Consumables & Equipment & $\begin{array}{l}\text { Software } \\
\text { purchase }\end{array}$ & Salary & Rent & $\begin{array}{l}\text { Software } \\
\text { renewal }\end{array}$ & Petty cash & Total cost \\
\hline 2010 & - & 23012519 & - & - & - & - & - & - \\
$2010-11$ & 2472244 & - & - & 2991298 & 1500000 & - & 960000 & 7923542 \\
$2011-12$ & 5686161 & - & - & 6879986 & 3000000 & 100000 & 2400000 & 18066147 \\
$2012-13$ & 6539085 & 46000000 & 448333 & 7911984 & 3000000 & 100000 & 3000000 & 66999402 \\
$2013-14$ & 7519948 & - & - & 9098781 & 3000000 & 100000 & 3750000 & 23468729 \\
$2014-15$ & 8647940 & - & - & 10463598 & 3000000 & 100000 & 4687500 & 26899038 \\
$2015-16$ & 9945131 & - & - & 12033138 & 3000000 & 100000 & 5859375 & 30937644 \\
$2016-17$ & 11436901 & - & - & 13838109 & 3000000 & 100000 & 7324218 & 35699228 \\
\hline
\end{tabular}

Total cost and total revenue is depicted in the Table 3. It shows that except for the years 2010 and 2012 to 2013, there is substantial net gain or profit. In these above-mentioned 2 years, cost is much higher than revenue due to heavy investment by the organization.

Net present value (NPV) for the project was calculated from 1 to 7 years based on the actual data of 3 years and projected data of subsequent 4 years. The NPV is calculated for the entire life cycle of the project but, in this case, we wanted to know the status of the project in the first 6 years of operation. After 2017, there may be expansion depending upon the performance of the center and market potential. Therefore, the NPV and PI for the project till 2017 are done to decide the future course of action.

$$
\begin{aligned}
\text { Net present value }(\mathrm{NPV}) & =\frac{\text { Initial investment }+ \text { Net gain }}{1+0.01^{\mathrm{n}}} \\
\mathrm{NPV} & =56918501
\end{aligned}
$$

A positive NPV explain the project is worthwhile and making profits, with current cost and revenue projections. The project can be further being taken further and the promoters may look for more opportunity by expansion.

$$
\text { Profitability index }=\frac{\mathrm{NPV}+\text { initial capital investment }}{\text { Initial capital investment }}
$$

PI for this center is 3.47 which shows that for every ₹ 1 spent, 3.47 rupees will be earned by the eye center.

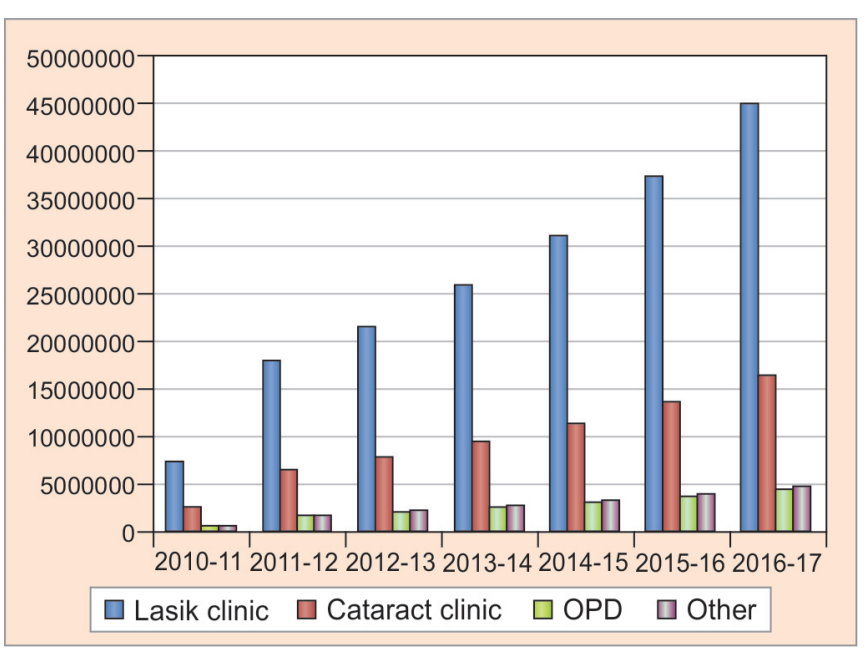

Graph 1: Year-wise revenue generation trend from different specialities
Result of PI and NPV interpret that the project is viable and successful.

\section{CONCLUSION}

This research gives a unique and valuable insight toward the cost centers and revenue generation centers of the eye care unit. Cost centers include the capital cost, running cost and the petty cash. The revenue centers are the different specialties offered by the center and OPD, diagnostic tests and surgeries within the specialty. Also, the NPV and PI of the project are positive, i.e. the project is viable and profitable. For each rupee spent, the eye center earns approx ₹ 3.5 .

Cost benefit analysis is one of the key items of any business case. It is the analysis of costs of a project that includes some consideration of both the cost and the payback in monetary terms. Measuring costs is an exacting process and relies upon clearly defining that the cost inputs selected for analysis are 'Measured in appropriate physical and natural units'.

The PI is also known as benefit/cost ratio. It is present value of future values (NPV) plus the initial investment, divided by the initial investment. The NPV is a discounted cash flow (DCF) technique. It relies on the concept of opportunity cost to place a value on cash inflows arising from capital investment.

Opportunity cost is the calculation of what is sacrificed or foregone as a result of a particular decision. It is also referred to as the 'real' cost of taking some action. Present

Table 3: Year-wise cost, revenue and net gain or profit of the eye center

\begin{tabular}{llll}
\hline Year & Total cost & Revenue & $\begin{array}{l}\text { Net gain } \\
\text { (profit) }\end{array}$ \\
\hline 2010 & 23012519 & & -23012519 \\
$2010-11$ & 7923542 & 11879180 & 3955638 \\
$2011-12$ & 18066147 & 28510038 & 10443891 \\
$2012-13$ & 66999402 & 34212044 & -32787358 \\
$2013-14$ & 23468729 & 41054454 & 17585725 \\
$2014-15$ & 26899038 & 49265344 & 22366306 \\
$2015-16$ & 30937644 & 59118414 & 28180770 \\
$2016-17$ & 35699228 & 70942096 & 35242868 \\
\hline
\end{tabular}


Table 4: Year-wise trend of revenue generation by different specialties

\begin{tabular}{lllllll}
\hline Year & Lasik clinic & Cataract clinic & OPD & Others & Total revenue (in ₹) & Data type \\
\hline $2010-11$ & 7507643 & 2760721 & 794717 & 816099 & 11879180 & Actual \\
$2011-12$ & 18018343 & 6625733 & 1907322 & 1958640 & 28510038 & Actual \\
$2012-13$ & 21622012 & 7950879 & 2288786 & 2350367 & 34212044 & Actual \\
$2013-14$ & 25946414 & 9541055 & 2746544 & 2820441 & 41054454 & Projected \\
$2014-15$ & 31135697 & 11449266 & 3295852 & 3384529 & 49265344 & Projected \\
$2015-16$ & 37362836 & 13739120 & 3955023 & 4061435 & 59118414 & Projected \\
$2016-17$ & 44835404 & 16486943 & 4746027 & 4873722 & 70942096 & Projected \\
\hline
\end{tabular}

value is the cash equivalent now of a sum receivable at a later date. If the money is not spent now and banked, the opportunity cost includes both the initial sum and the interest earned.

NPV is a technique where cash inflows expected in future years are discounted back to their present value. This is calculated by using a discount rate equivalent to the interest that would have been received on the sums, had the inflows been saved. A positive NPV means that the project is worthwhile because the cost of tying up capital is compensated for by the cash inflows that result. When more than one project is being appraised, the project with the highest NPV is taken up.

In this study, total costs and revenue data is analyzed to calculate the year wise net loss or net gain of the eye center. Total initial capital investment of the project is ₹ 23012519.18. Ninety-five percent of the initial capital investment is done on the equipment. Analysis of the cost centers data from 0 to 3 years revealed that petty cash, consumable cost and salary showed a 25, 15 and $15 \%$ increase respectively, on annual basis.

Analysis of the revenue of the 1 to 3 years showed that there is approximately $20 \%$ increase in the revenue every year. The analysis of 2012 to 2013 revenue data showed that Lasik clinic and cataract clinic contributed 63 and 23\% of the total revenue generated in the year.

The center suffered a net loss in the 3rd year due to huge capital investment on equipment and software. For the rest of the years, the center shows net gain and is profitable.

Net present value calculated for the project for 7 years is 56918501. A positive NPV means that the cash flows will be positive. NPV is basically a tool to determine whether a decision or project of a firm will add value to it or not. When the NPV $>0$, this means that the investment will add value to the firm and may be accepted. However, it must also be remembered while looking at the NPV that time is also a factor. In this case, the NPV for the eye center project is calculated based on the 7 years data so the NPV value tells that the project will be profitable at time ' $t$ ' which is 7 years in this case.

When the present worth of all future cash flows exactly equals the initial investment, the NPV would be zero (because there is no rupee amount difference) whereas the PI would be 1.0 (because there is no proportionate difference). Profitability index measures the ratio between cash flow to investment. Therefore, the higher the ratio the more cash flows to investment. Profitability index $=1$ means that the desired rate of return have been achieved (i.e. the price paid for the project based upon its future cash flows discounted at rate of return is exactly right). In case of our center, the PI is 3.47. It means that the center has exceeded its goal. For each penny spent, ₹ 3.47 will be the earned amount.

NPV reflects the net increase in firm's wealth and PI gives a ratio. In case of this eye center, both the NPV and PI are positive which means that the project is viable and is profitable.

\section{LIMITATIONS}

This study was based on actual data of two and a half years and projected data of 4 years. The outcome of the research could be more accurate and precise if there had been more actual data as compared to the projected data.

\section{REFERENCES}

1. MMU Cost Benefit Analysis toolkit. Available at: www.mmu. ac.uk/bit/docs/Cost-Benefit-analysis-toolkit-v2.pdf.

2. Shiell A, Donaldson C, Mitton C, Currie G. Health economic evaluation. J Epidemiol Community Health 2002 Feb;56(2):85-88.

3. Brien BO. Principles of economic evaluation for health care programs. J Rheumatology 1995;22:7:1399-1402.

4. Holtzer-Goor KM, van Sprundel E, Lemij HG, Plochg T, Klazinga NS, Koopmanschap MA. Cost-effectiveness of monitoring glaucoma patients in shared care: an economic evaluation alongside a randomized controlled trial: BMC Health Services Research 2010;10:312.

5. Brown MM, Brown GC, Sharma S, Landy J. Health care economic analyses and value-based medicine: Survey of Ophthalmology 2003;48(2):204-223.

6. Sculpher M, Drummond M, Buxton M. The iterative use of economic evaluation as part of the process of health technology assessment. J Health Services Resear Policy 1997;2:26-30.

7. Article on 'Profitability Index: a finance ranking tool'. Available at: www.financescholar.com.

8. Smith AF, Brown GC. Understanding cost effectiveness: a detailed review. Br J Ophthalmol 2000;84:794-798.

9. Cairns J. Nuffield occasional papers: economic evaluation and the healthcare: health economics series: Paper no. 7. 1998. 